\title{
Light Saver: Wearable LEDs to Hunt, Reward, Show Off and Equalise
}

\author{
Katrine Løck Worm, Dora Vagner, Camilla Schibsbye, Robb Mitchell \\ University of Southern Denmark \\ Kolding, Denmark 6000 \\ kawor13@student.sdu.dk, dovag13@student.sdu.dk, casch16@student.sdu.dk, robb@sdu.dk
}

\begin{abstract}
Differences in children's skills and physique can impede their enjoyment of physical games. In this paper, we present a wearable system for playing tag in the dark. We intended the LEDs on players' vests to balance differences in children's abilities by increasing the visibility of more successful players. Initial tests with 64 children suggest that lighting effects may have indirectly produced an ability equalizing effect through prompting in-game communication about cooperation. In our design, very simple lights functioned as a distributed on body scoreboard while simultaneously offering other effects such as providing reward, motivation and illumination. We hope this design may give inspiration to developers concerned with playing balancing and wearable game platforms.
\end{abstract}

Body games. Wearables. Ability balancing. Children.

\section{INTRODUCTION}

Many children much enjoy physical games in lowlight conditions. A classic handbook for the Scouting movement goes so far as to say "nothing beats" playing in the dark (Sweet 1951). Vongsathorn et al. have argued that darkness can "free up possibilities" for bodily movements, i.e., people's actions not being observable can reduce self-consciousness and social inhibitions (2013). Similar effects have been reported also in sensor based playground games that Grogan identified that children as young as eight years old can suffer from issues of body consciousness (2016). So although the Kinect study of Vongsagthorn (ibid.) was concerned with adult participants, we see these emancipatory effects of darkness as potentially very beneficial for increasing some children's participation and enjoyment in physical activities. In particular we see a potential for dynamic lighting effects in low-light conditions to not only increase excitement but also to discretely provide ability-balancing mechanisms in physical games. We have begun to explore this through the design and preliminary testing of Light Saver - a wearable LED platform for playing tag games.

\section{RELATED WORK}

Many organised sports such as golf or horse racing have long incorporated a "handicapping" feature. This gives players of different abilities a more evenly matched challenge through varying the conditions for competitors in advance of a contest.
Computer games offer a range of possibilities for adjusting difficulty levels (2005), and in recent years digital-physical play designers have pursued similar aims for balancing the challenges between mismatched opponents in physical sports and playground games. Altimira et al. (2017) experimented with a digitally augmented table tennis table to balance the abilities of different (adult) players. They make useful distinctions between restricting the performance of more skilled players and altering the style of their play. Their approach was to vary the size and position of playable zones on the table surface. However, this technique seems less promising for children because of the necessary visibility of such adjustments.

Children can be very sensitive concerning status with their peers. Thus the differential ranking of players' abilities that any handicapping implies can be a source of stigma in itself. Likewise, in studying an exergame with adults, Gerling et al. (2014) found that more explicit means of balancing players' abilities were associated with reduced selfesteem for the less skilled. Whether through providing additional visual noise, or cognitive puzzles concerning their functioning and accuracy, there is a risk that any balancing systems that augment playing surfaces may over-occupy the attention of players. This seems detrimental to the potential for new technologies to foster play experiences in which bodily and social engagement is the main source of pleasure (Márquez Segura et al. 2013).

Van Delden et al. have created several impressive versions of the game tag in an interactive 
playground. In a recent version (2017), to challenge more confident players, they provided an additional layer of gameplay via offering a projected representation of "particles" that a player could collect by approaching someone attempting to tag them. Earlier versions also used projections onto the floor, but with an intention to increase the saliency of particular players (Van Delden et al. 2014). All these designs, however, do require a very elaborate setup, and perhaps a reliance on looking downwards to floor projections can reduce some of the eponymous benefits of "heads up play" (Soute 2007). Games that involve restricting the visual perception of some players (e.g Finnegan et al. 2014) seem promising for equalising some aspects of physical prowess, but we have yet to such a game in which blindfolds or visibility are dynamically adjusted.

\section{LIGHT SAVER WEARABLE PLATFORM DESIGN}

To explore possibilities of game balancing for children's digital bodily play, we developed a wearable gaming system. Each player wears our bespoke "Light Saver" vest (figures 1 and 2) incorporating four main electronic components. Namely, an RFID chip stitched on one shoulder, a concealed Arduino 101 microcontroller, a strip of 6 LEDs across the chest, and an RFID RC522 reader strap that is strapped to the palm of the right hand. Each chip has a specific identifier, which will tell the Arduino to turn on a specific LED in a unique color in the LED strip of other players. This enables players to "collect" the colors of other players by bringing their RFID chip into contact with the RFID reader of another player.

In the version we deployed, six participants each wore a "Light Saver" vest. We explored a six-player game because this offered a sufficient quantity of people for complex social behaviors, while not so large that it is difficult for each player to have distinct LED colors. The aim of the game is to tag all the other players so that the winner is the first player to tag everybody. At the beginning of a game, players "have" their own color, or in other words, the LED strip on each vest displays a unique RGB value. When a player tags another player by touching the chip of another player with the RFID reader in the palm of their hand, the vest of the tagger will display an additional LED - the same tone as the color of the tagged player. Once a LED color on a particular vest is activated, it remains illuminated until between the reader and the same chip. We designed version for playing in the dark in an attempt to maximise the visual impact of the LEDs and create an ability balancing effect. With this setup, the more a player succeeds in tagging others, the more lights on their chest are illuminated, thus making such a player much more visible, and therefore potentially vulnerable to their opponents.

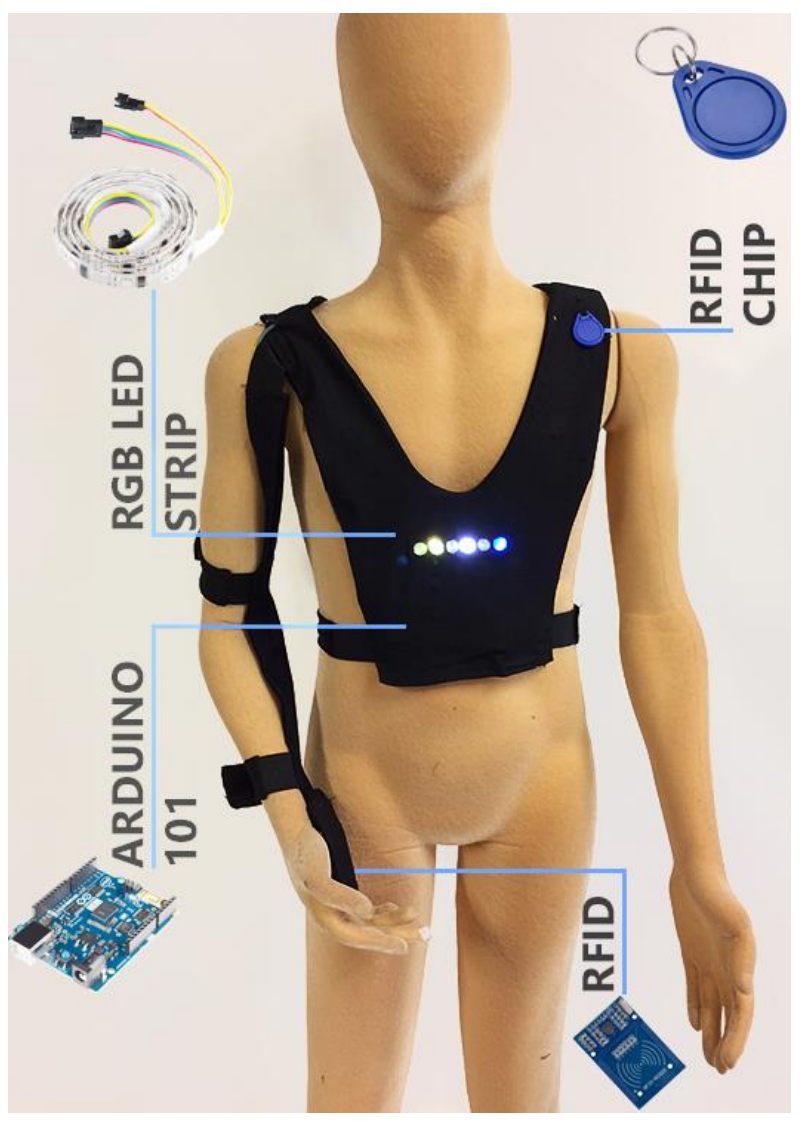

Figure 1: The Light Saver vest and its components

\section{TESTING}

"Light Saver" was tested at a public, elementary school in a Danish town, following the obtaining of appropriate consent. The indoor playing area of approximately $40 \mathrm{~m} 2$ was made very dark with blackout curtains, but it was not completely dark due to a thin crack in the curtains and an emergency exit light at the far end of the room. The school's head teacher carefully approved these conditions for our playtest, and at least one class teacher was present at all times to monitor safety issues. We tested 64 children in mixed gender groups from three different classes ranging in age from 7-12 years old. The children only played with their similarly aged peers. A total of 13 rounds were played (table 1). The room lights were on while children put on their Light Saver vests and listened to a brief explanation of how to play. Then we turned the room lights off.

Three researchers directly observed each playtest and took brief notes. After each game, children participated in a short semi-structured group interview in which we asked about their favorite and least favorite aspects of the game. Video 
recordings of the play sessions were subsequently reviewed repeatedly with particularly close attention paid to the soundtracks, including detectable emotional qualities of children's utterances and the frequency and distribution of utterances between different children over the course of a game.

Table 1. Overview of play test sessions.

\begin{tabular}{c|c|c|c} 
Age & Rounds & $\begin{array}{c}\text { Average } \\
\text { duration. } \\
\text { (min.sec) }\end{array}$ & $\begin{array}{c}\text { Average } \\
\text { number of } \\
\text { kids }\end{array}$ \\
\hline $7-8$ & 3 & 6.08 & 4.33 \\
\hline $9-10$ & 5 & 4.26 & 4.6 \\
\hline $11-12$ & 5 & 5.16 & 5.8
\end{tabular}

\section{FINDINGS}

Thematic analysis of observations, video analysis and interviews all indicate that the game was very enthusiastically received. Our initial visual impression at the time was it was like being at a disco or looking at fireflies swirling around. We were also struck by a massive increase in volume when the room became dark.

\subsection{Enthusiastic Exertion and Exclamations}

With only a couple of exceptions, it appeared that all children were very energetically participating throughout every session. This observation was corroborated by the feedback sessions in which "running" was mentioned most frequently as the favorite thing. Nearly all instances of the game followed broadly similar basic dynamics of three phases. An initial high-volume stage of excited shrieking and laughter when the ceiling lights were turned off, and players start to run around. Followed by a quieter but still energetic phase in which most children appeared to concentrate on improving their performance in the game. The third and final stage was also very noisy as children often made frantic exclamations regarding endgame matters such as who was winning and how to stop those in the lead from winning.

\subsection{Dark and light as camouflage and catalysts}

The wearable lights and being in the dark were the second and third most frequently mentioned favorite aspects of the game. Being in the dark seemed to have a liberating effect in igniting raucous behavior that appeared to be almost random initially. Analysis revealed many different ways that players adapted to the conditions. The darkness, and the attention given to the LED displays meant that children were frequently unaware of the identities of their opponents. This resulted in many instances of children initiating fast paced dialogue with unseen peers concerning their statuses and intentions in the game, including identity blind offers to "trade" colors. Most children seemed "proud" of the colors they collected, some screaming 'yes!' when they got a new color. Even after the room lights were turned back on, the children who had not collected all the colors, would try to get the ones they were lacking. Several of the winning children were seen paying extra attention to their colors by looking down at them several times after they had won. They would also keep their arms and hands away from the vest and straighten out their back a bit, when huddling up with the rest of the children for the feedback sessions. In the test session with an audience, one of the winning children took a kind of "lap of honor" showing off his colors to the audience. In feedback sessions, several children mentioned collecting colors as one of their favorite game aspects.

\subsection{Defensive Strategies}

One boy in the age group of 9-10 seemed aware that he was faster than the rest of the players and spent most of the time running far from the other children, thus ensuring that the others did not tag him, but this "defensive" strategy also resulted in him tagging very few other players. A girl in the oldest age group (11-12 years) tried a different defensive strategy by remaining stationary but with arms outstretched to fend off any taggers. This resulted in her color being the last one needed by the other players, so she also became surrounded at the end of the game. In the third session, with players in the age group 11-12 years, several players spent most of the game with a hand on their one shoulder blocking the RFID chip and thus preventing any one catching their color. The fellow session members mentioned this blocking behavior as being their least favorite aspect of the game. To address this, in introducing subsequent sessions, we improvised and attempted to impose an additional rule that players must always keep one hand behind their own back. This requirement was almost completely ignored once the lights were turned off, but the blocking tactic did not re-occur frequently.

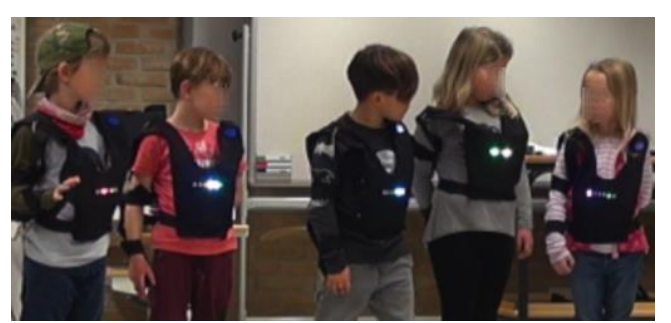

Figure 2: Five Light Saver vest wearers discuss their experiences of playing. 


\section{DISCUSSION}

It is difficult to pinpoint which elements or factors were most important to the apparent success of the game. The evaluated experiences can be considered as a combination of two main ingredients: tag and playing in the dark. Both these ingredients can be very appealing in their own right. Low light conditions are very well established as a route to heightened play and other leisure experiences (Vongsathorn et al. 2013). It seems likely that playing any version of tag in the dark without LEDs might also have proved exciting for our test participants. However, health and safety of children is a top priority in school sports - teachers are generally loath to permit playing high speed, competitive games in low light conditions. Body worn LEDs certainly increase the safety of physical play in low light conditions in addition to providing attractive, atmospheric effects, player motivation and status displays.

\subsection{Game balancing mechanism via social communication}

The wearable displays seemed very much to keep players' attention upon each other. As the vests provide the main and most colorful light sources in the room, this is not surprising. Since the lights are continuously moving in unpredictable fashions, these lights are very eye-catching. It appeared to us as observers that players who collected more colors were more visible than those who activated few additional LEDs. However, it is not clear whether such variations in vest brightness were apparent to children while playing. For a player to track the current "score" in the game seemed very challenging, since this requires monitoring displays of six fast moving light sources.

Most players seemed very quick to change tactics when an opponent was close to winning. This was not a result of all players viewing the lights, as it was quite often the case that one player would notice the emergence of a "leading scorer" and shout a warning to others about this. Thus the ad hoc teamwork that emerged frequently required communication about the light statuses rather than happening solely in direct response to the lights. This phenomenon seems worthy of further study and experimentation with technological possibilities to enhance pleasure and learning concerning social coordination in body based games. With repeated play, however, players might develop strategies involving bluff and deception regarding the status of others. So we also see the importance of understanding better how to design distributed on body scoring systems for instance through experimenting with quantity, brightness, position and other properties of LEDs or restricting players' verbal communication. A similar player behavior of unifying against a leading individual is a phenomenon seen in board games (e.g. in Risk and Monopoly), informal sports, and traditional playground games. However, what wearable digital technology offers is the capability to dynamically display leaderboard information in ways that do not distract from physical play experiences.

\subsection{Further Work}

Identifying if Light Saver might offer an effective dynamic ability balancing mechanism requires much further testing. Primarily it is necessary to identify the relative skill and ability levels of subjects in playing physical games under standard conditions. In addition, play testing a simple version of tag in the dark, lit by on-body but non-responsive LEDs will help us better understand any potential impact from the interactive lighting. We also plan interviews with teachers and playground supervisors to obtain their impressions on how our game platform affects their pupils' play. Experimenting with brighter and more dynamic LEDs should also help clarify what impact different aspects of our concept may have on player experiences and social dynamics. Adding more LEDs, and experimenting with their position on the body seems likely to affect possible abilitybalancing. For instance, if a high performing player has a highly illuminated back, they may be more easily tagged than when displaying similar brightness on their front. Although we need to carefully consider the safety implications of making other body parts "taggable".

\section{CONCLUSION}

We have presented the design of a wearable game platform and a preliminary evaluation of children playing our tag game in the dark. Based on our study, it appears the balancing of physical games appears addressable through provoking collaboration against players who take the lead in the game. Distributed on-body scoring displays appear to have a potential for provoking children into exertions and mutual engagements. We acknowledge the novelty of the dark environment probably had a major impact on the positive reception of the game. This makes the design seem less promising for deployment in most of the places children regularly play. However, since groups of children usually need adult help or permission to enter very dark spaces, the best direction for developing on-body lighting display systems like Light Saver could be towards supervised sports and games sessions in elementary schools. 


\section{REFERENCES}

Altimira, D., Clarke, J., Lee, G., Billinghurst, M., Bartneck, C., 2017. Enhancing player engagement through game balancing in digitally augmented physical games. International Journal of Human-Computer Studies 103, 35-47.

Gerling, K.M., Miller, M., Mandryk, R.L., Birk, M.V., Smeddinck, J.D., 2014. Effects of balancing for physical abilities on player performance, experience and self-esteem in exergames, in: Proceedings of the SIGCHI Conference on Human Factors in Computing Systems. ACM, pp. 2201-2210.

Grogan, S., 2016. Body image: Understanding body dissatisfaction in men, women and children. Taylor \& Francis.

Finnegan, D., Velloso, E., Mitchell, R. Mueller, F.F., \& Byrne, R. 2014). Reindeer \& Wolves:

Exploring Sensory Deprivation in Multiplayer Digital Bodily Play. CHI PLAY - Annual Symposium on Computer-Human Interaction in Play, ACM, pp. 411-412

Hunicke, R., 2005. The case for dynamic difficulty adjustment in games, in: Proceedings of the 2005 ACM SIGCHI International Conference on Advances in Computer Entertainment Technology. ACM, pp. 429-433.

Márquez Segura, E., Waern, A., Moen, J., Johansson, C., 2013. The design space of body games: technological, physical, and social design, in: Proceedings of the SIGCHI Conference on Human Factors in Computing Systems. ACM, pp. 3365-3374.

Soute, I., 2007. HUGs: head-up games, in: Proceedings of the 6th International Conference on Interaction Design and Children. ACM, pp. 205-208.

Sweet, J., 1951. More Patrol Activities. Boy Scouts Association.

van Delden, R., Moreno, A., Poppe, R., Reidsma, D., Heylen, D., 2017. A thing of beauty: Steering behavior in an interactive playground, in: Proceedings of the $2017 \mathrm{CHI}$ Conference on Human Factors in Computing Systems. ACM, pp. 2462-2472.

Van Delden, R., Moreno, A., Poppe, R., Reidsma, D., Heylen, D., 2014. Steering gameplay behavior in the Interactive Tag Playground, in: European Conference on Ambient Intelligence. Springer, pp. 145-157.

Vongsathorn, L., O'Hara, K., Mentis, H.M., 2013. Bodily interaction in the dark, in: Proceedings of the SIGCHI Conference on Human Factors in Computing Systems. ACM, pp. 1275-1278. 